\title{
The theory of interpersonal communication in S. Kierkegaard and the modern understanding of the problem of the philosophy of communication
}

\author{
Elena Fedorova* \\ Don State Technical University, 344000, Rostov-on-Don, Russia
}

\begin{abstract}
The article deals with the problems of the origin of the theory of communication in the philosophy of S. Kierkegaard and reveals a modern understanding of the problem of the philosophy of communication. The first part of the article shows the philosophical foundations of interpersonal communication, analyzes the theory of communication of S. Kierkegaard and the practice of media criticism. The second part of the article is devoted to the explication of the basic concepts of social media research (new media, network society, philosophy of social networks). The third part of the article presents the results of a survey of students regarding their attitude to modern communication practices. The influence of social networks on the everyday communicative behavior of young people is revealed. A survey of 40 Russian students found that while students are aware of the impact of social media on their daily communication patterns, they perceive them as a new natural medium of communication. The main conclusion is that although young people are aware of the impact of social media on their everyday communication patterns, they perceive them as a new natural environment for communication.
\end{abstract}

\section{Introduction}

"Anonymity in our time undoubtedly has more importance than it is probably realized; it reaches almost epigrammatic meaning. People not only write anonymously, but do it even by their own signature. Moreover, they even speak anonymously" [7], that was written in the $19^{\text {th }}$ century Danish philosopher Søren Kierkegaard's literary review "Two Ages". Paradoxically, but exactly these lines correspond to the modern communicative situation, mainly characterized by the widespread use of social media (Facebook, Twitter, YouTube, Instagram, etc.) and fundamental changes in communication styles and content transfer. Thus, the most important goal of the article presented is to trace some of such changes and outline the new ways of communication (various factors, e.g. globalization, digital interconnection, network community, consumer community, philosophical perspectives of Facebook links, etc.).

\footnotetext{
*Corresponding author: bulusheva90@gmail.com
} 
At the beginning of the article communication philosophy are regarded; in the second part the basic concepts of communication science (concepts of new media, network society, digital society, etc.) are considered. In the third part the outcomes of students' empirical survey are presented.

\section{Communication Philosophy}

Throughout the history of philosophy in the West, the communication problem has acted an outstanding role, starting with the fundamental work of Aristotle "Rhetoric". In this work not only the form of communication is regarded, but its content as well, that is, what must be communicated; besides, Cicero's "Orator" may be mentioned here with a description of the types of speakers. Nevertheless, communication as a philosophical problem itself arises in the $19^{\text {th }}$ and $20^{\text {th }}$ centuries among such thinkers as Søren Kierkegaard (the concept of existence-communication as ability to interact against objective knowledge communication), Edmund Husserl (the problem of inter-subjectivity in the $5^{\text {th }}$ Cartesian meditation), Paul Ricœur (the problems of narrative, time and understanding), Max Scheler (values communication), Martin Heidegger (being-in-the-world and co-being), Alfred Schütz (theory of inter-subjective understanding), Karl Jaspers (communication in the fact of existence), Martin Buber (communication as a dialogue), Emmanuel Lévinas (communication at the face of another), Jürgen Habermas (communicative rationality), Jacques Derrida (linkva and password, deconstruction and differentiation), Marshall McLuhan (environment is a message), Ludwig Wittgenstein (language games), Roland Barthes (cultural semiotics), Jean Baudrillard (new sign systems), Charles Sanders Peirce (communication pragmatics), etc. All of these different approaches mentioned above have a general bearing on such or another relying on information. In the present study devoted to the social media influence on patterns of interpersonal communication, we propose to use Søren Kierkegaard's theory of communication and the practice of media criticism as a philosophical foundation.

Although we can easily imagine the life path of Søren Kierkegaard as a periodic, but consistent reaction to certain negative features of his epoch, it is still obvious that he diagnoses the disease of the epoch itself. This "disease to death" is not only a crisis of faith (although this is the most striking symptom), but also the entire complex of relationships, including science, technology, politics, social action, philosophy and finally religion. To put this another way, he pays attention to what we today name "modernity", which is dangerous just because of the single fact the it levels individuality and immerse in abstract intellectualism, despite the concreteness in general and the concreteness of individualism. It was taken for granted that reflection has the biggest value; science slowly deviates from the primitivism of being; nothing exists which we can feel or experience, everything is ordered in a special system and into different classes of abstract thinking. The human being is no longer capable of love and action, except the devastating rational thinking encouraged by the new media.

Kierkegaard's relationship with the media is complex and has rather personal imprints, especially if the 1846 Corsair Case is recalled, which centered on his personality. Kierkegaard has undergone a massive media attack, paparazzi-style publicity like some modern celebrities. As for some of them, the suggestion exists that this scandal could be provoked by himself. Roger Poole put forward this point of view in his monograph "Kierkegaard: Indirect Communication" [10].For several months, not a single issue of the Copenhagen satirical magazine "Corsair" came out without pamphlets or caricatures sarcastically depicting Kierkegaard's external oddities (for example, his slightly hunched back or different trouser-legs lengths), directly or indirectly ridiculing his remarks. It seems that disgust for the daily press may be the result of these ill, hurtful and too personal 
emotions and feelings. Nevertheless in his autobiography "The Point of View of My Work as an Author" Kierkegaard claims that he modeled his daily actions and reactions to everything that happened around in accordance with the tasks of authorship. "Through my own personal existence, I tried to support the pseudonymous writers and all aesthetic writing" [1]. In other words, being depressed, Kierkegaard appeared at public events every day for at most a few minutes in order to demonstrate his bohemian carelessness, although this was all lies. Till creating religious works he sets himself (according to his autobiography) as the object of the gaze and stare of ordinary people. "I realized immediately that my personal existence must either correspond to this, or I must make an attempt to form a different impression of my existence between my contemporaries" [1]. The above confessions of the philosopher, in our opinion, allow to look at the relationships between Kierkegaard and the press, with an emphasis on aspects such as publicity and social reality construction, individuality decreasing and loss, anonymity and in the end noise. The aspects mentioned give all the grounds to consider Kierkegaard from the point of view contemporary media critique and research in the field of social media.

The first public speech of Kierkegaard about the role of the media in society and its influence on it was read as early as 1935 in the form of a lecture to a student association on the topic "Our Journalistic literature". Four theses were discussed then:

1) Talented individuals among journalists can be founded, but for the most part they are all incompetent;

2) Free press has no significant role in Denmark liberalization, the greatest merit here belongs to King Frederick IV;

3) The import of foreign ideas contributes to the too hasty development of the country;

4) The anonymity of the authors of newspaper articles can turn people into irresponsible individuals, and the information may not be accurate enough [10].

Four our study the latter aspect has particular importance, because communication anonymity (pseudo-anonymity), the speed of information spreading, significantly change the way we interact and communicate. This is precisely what modern media philosophers point to. Here let us mention Marshall McLuhan's famous expression "communication mean" and his distinction between "hot" and "cold" media. "In a culture like our one, which has long been accustomed to splitting and dividing all existing as a mean of control, the reminder that a message can be a practical mean of communication sometimes becomes simply shocking"[4].

It simply means that social or personal effects of any media - that is, any expansion of ourselves - come from new dimension which enters our affairs by our own expansion or any new technologies. To put it differently, the way of communication affects its content and the communicators themselves. "Cold" media, according to McLuhan, require participation and engagement in opposition to "hot" media. We must remember that this was said as early as in 1964, but as we are going to see later, the concept of "cold" media resonates strongly with the concept new media by Paul Levin.

"Two Ages" is work by Kierkegaard written in 1846 in the form of critical essay that examines Thomasina Guillembur's novel "Two Ages"; the philosopher took this novel for the basis of developing his personal opinion about the "ghost of the public" [1]. Describing his era through the prism of communicative activity Kierkegaard states: "... the modern epoch is the epoch of advertising and a wide variety of announcements: nothing takes place, but what does - is just an instant notification. The division between private and public comes to the end, the private turns into the public, and individuality is reduced. The press begins to play a significant role in such processes that has all the possibilities of making a person both a one-day hero and an object of public ridicule. It is very difficult to find any reasons for this, because there is no individual responsibility at all". To illustrate the above statement, Kierkegaard cites the example of a Roman emperor who let dogs to tear innocent 
people to pieces; the blame ultimately rests with the dogs. In the same manner public tears to pieces the ones who are brave to be different. "The abstraction of the press (for a newspaper, magazine, there is no political specifics and only in an abstract sense an individual) combined with the dispassion and reflexivity of the epoch gives rise to a phantom of this abstraction, the public which is a real equalizer"'77]. Kierkegaard's political conservatism makes him look at the developing rise of social egalitarianism with some suspicion, as "more and more individuals will strive to be nothing" - in order to be a public this abstract whole is formed ridiculously by a participant who becomes a third party. As a result, a kind of negative sociality arises, where relations between individuals are rooted only in abstract principles.

To sum up we may say that, according to Kierkegaard, the ailments of the epoch are the following ones: the rise of an egalitarian society; leveling of public opinion that the media forces; growing reflexivity and dispassion; individualism decrease; true interpersonal interaction is possible only between certain individuals.

Individuality Leveling and Loss. Kierkegaard criticizes the press, which acts a significant role in shaping consciousness of ordinary people, because the journalist can say whatever he wants; the resemblance of the truth is achieved by advertising itself.

Thus, if any dialogue exists, it performs between anonymous participants. A nonindividual is a member of the crowd, one of many others, who was undergone a leveling process. "... Leveling is an abstract force and the victory of abstraction over individuals" [7].

Nevertheless, an individual is someone who can resist society, but, perhaps, being too concerned with his external manifestations, he seeks to stand out and is inclined to neglect his inner self (yet he has the potential for this). The public is false construction created by the media, and this false construction makes any true communicative act impossible.

Anonymity. The links between narrator's position and the narrative itself are torn, thus the narrative is objectified, depersonalized. Anonymity is the evasion of ethical responsibility to others and to oneself.

Isn't this similar to today's anonymous on-line writings? Kierkegaard writes: "The press is often guilty of its tactics in the petition of the principii; hiding behind allegedly messaging of an actual situation, it really aims at producing it by its own. There is something that a journalist wants to promote, but perhaps there is no one at all who thinks or cares about it; what is left for a journalist? He writes an article in spiritual tones that this is a deeply felt need by everyone, etc. His newspaper begins to be published in wide circulation, and the game starts. The article is read and discussed, and some other article will probably be written against it, then a polemic will arise and there will be a sensation..." [1].

Noise and Publicity. Kierkegaard sated that the press creates continuous background noise. Information expansion speed (and this in the days of Kierkegaard!) creates a superficial effect when everything is small and unimportant. Printed works content matches tastes of the average (ordinary) person as only by this the sales can be increased. "Ah, everything is so noisy; like hard drinks that stir up the blood, nowadays everything else, even the most insignificant and empty projects and communication, have the single purpose - to shake up feelings, excite the masses, move the audience, make a noise! And this clever fellow - a man - became apparently sleepless, just to invent endless new tools to amplify and spread noise and insignificance with the greatest possible haste and on an incredible scale. Yes, too soon everything is turned upside down: the message is brought to the lowest point in terms of meaning, and at the same time its means are brought to the highest point in terms of general circulation; for everything published with such ardent haste is more widespread than rubbish! Oh, create silence!” [1]. According to Kierkegaard the only possible counterbalance to these destructive factors is individual's self-consciousness since 
the equality between identically produced individuals does not exist. True combined communication is possible only between specific, historical and contemporary personalities. Thus, Kierkegaard's philosophy of communication is important in understanding the current situation in interpersonal communication.

\section{Social Media and Communicative Research}

Some several fundamental concepts related to the modern communication research are explained in the second part of the article. Among the most important ones there are "new media" by Paul Levinson and "the network society" by Manuel Castells and Jan van Dyk.

New Media. New media have five distinctive characteristics: digitalization dematerialization of the media text; convergence - new media bring together the information forms and functions, media, electronic communication and computing; freedom in the (re)production of content and information form in interaction process (interactivity); hypertextuality - a new life experience of a person, leading to the transformation of economic activity, cultural attitudes, forms of interaction and other aspects of society; virtuality - virtual community creation that crosses human society boundaries that will undoubtedly challenge our reality perception and have a traditionally defined identity [9].

New Mass Media. Paul Levinson became the first author who proposed this concept in his book "New New Media" may seem somewhat confusing at the first glance, but the author emphasizes that it has a special meaning, that is it denotes new media and communication tools that imply interactivity and reciprocity (in comparison with McLuhan's concept of "cold" media). They have appeared over the past five years and are newer than classic new media in the form of e-mail and websites. What are the basic principles behind the new media? (1) Each consumer becomes a producer - readers become writers, and producers become actors; here we can mention an example like Wikipedia, which can be developed by anyone; in a certain sense, it embodies the spirit of new media itself, namely, we can find primary information and links there, but this source is considered unreliable for academic research. (2) Lack of professionalism. While new media can be used for profit, this is not the main aim; they acquire authenticity precisely because writers do not work for some organized newspaper. (3) Free choice of environment. Facebook and Instagram - new media allows choosing any way of expression or different tools combinations, e.g. Twitter and Instagram, YouTube and Facebook, etc. (4) Free. As a rule, new information mediums are free of charge for users and producers. (5) Communication compliance and competition, e.g. Google users tend to have a common account for G-mail, YouTube, Facebook, etc. (6) Social nature. New media are inherently social; they help to develop new communities and specific subcultures with their special ways of communication [8].

Network Society. The book "The Rise of the Network Society" by Manuel Castells begins with the description of information technology revolution differences from industrial revolution. A distinctive feature of the new IT paradigm, especially affecting socioeconomic transformations, is its "Network logic". New information technologies facilitate much more complex communications within networks. "The shift from traditional media to horizontal communication networks centered on the Internet and wireless communications has caused many new communication patterns, being at the core of a fundamental cultural transformation, because it is virtuality that is becoming an essential dimension of reality today"[3]. Castells describes the changes of the past two decades, the most significant of which is the merging of the Internet and wireless technologies (mobile Internet and Wi-Fi are widely used today; anywhere people sit with their mobile phones or tablets and surf the net). "New technologies give opportunity to develop virtual reality spaces that 
simultaneously combine communication skills and experimentation in role-play”. Jan van Dyk presents slightly different approach in his work "The Networked Society. Social Aspects of New Media". The network society, according to Van Dyck, is a new type of society where mediation technologies form a communication network influence society, but personal social relation do not influence the networks. He distinguishes network and information societies by highlighting their focuses (information society focuses on the changing content of social processes, network society considers the organizational forms of social processes). "The $21^{\text {st }}$ century with only a slight exaggeration can be called the century of networks becoming the nervous system of modern society. It is expected that such infrastructure will have a much greater impact on the entire personal and social life of modern people than the construction of transport roads for passengers and goods in the past. In this sense, it is most rational to use the term "information highway" as it is quite appropriate. The design of the basic infrastructures described is critical in providing the associated risk opportunities" [6]. Thus, social and media networks creates a very strong new society infrastructure; this explains optimistic vision of public sphere fragmentation: "therefore, I am less than most observers afraid of the fragmentation of its public sphere due to the increase in the number of subcultures that communicate completely separately from each other when using new media" [6]. Van Dyck also argued that the growth of individualization is especially evident in modern high-tech societies. In this context, the rise of individualism becomes a counterpoint to the growing prevalence of the web, i.e. anyone can access the web and form a specific community.

Facebook Philosophy. In "Facebook and Philosophy" (a symposium titled "Facebook and Philosophy") the philosophical aspects of this social network are revealed, which has become much more than just communication tools and environment; namely, it became a community with its special rules of behaviour, written and unwritten codes of ethics, as well as special proficiency in language and symbols (which were hardly understood by those who lived before Facebook/before Zuckerberg).Facebook is the combination of several philosophical issues: privacy issues (although Facebook itself is in the public domain, a profile is a private area that needs to be protected), personal profiles and photos (information that we post in the network may be available to potential employers; postures and the scenery on the photos speak louder than words), friending (a special concept used by the book authors to describe the phenomenon of friendship on Facebook; are they true friends? - rather not), excess of vision, playing with identities. "Facebook seems to be rather effective tool not only for creating new social contexts, but also for their destruction. Because its servers, which make it easy to share information within your network of college friends, creates all the possibilities of easy copying and pasting your words into e-mail as well'[11]. This can easily lead to unintended sharing and loss of privacy. Communication patterns have changed dramatically, and the question is: do these changes provoke changes even in the daily language use?

\section{Students Attitude Towards New Forms of Communication}

Text messaging has become more widespread over the past decade, "text is spoken by", a new form of written vocabulary has emerged [5]. The text of the messages resembles the standard language, and both can be considered written languages; however, there are marked structural differences between them. More specifically the communication text is characterized by abbreviations, smileys (symbols representing emotions, for example for "happiness") and removing unnecessary words, vowels, punctuation marks, and capital letters; words are often encoded in a simple phonetic form. In addition, capital letters and punctuation marks are often overlooked. Even to describe these new forms of written discourse, a special term was developed - "textism". Today we can talk about social media 
grammar, specific punctuation, spelling, etc. Text messaging refers to abbreviations and other techniques to create SMS and instant messages. Text messages do not always follow standard grammar rules as well as the usual spelling. They are so common that they are considered by some to be an emerging linguistic register.

To study the attitude of Russian youth towards texts and other forms of expression on the Internet (in particular, on Facebook, Twitter and e-mail) we conducted a survey of 40 students. The selection of the sample was substantiated by statistical information, i.e. for example in 2018, two age groups clearly dominated among Internet users - 16-24 years old and $25-34$ years old $(96,8 \%$ and $95,8 \%$ respectively). To narrow the group, we chose a survey of students (they fit into the age range of maximum users), $n=40$, who study at courses in philosophy, communicative ethics, communicative management, and intercultural communication. The results obtained can demonstrate a general trend in relation to communication patterns.

The questionnaire consists of 6 closed questions. In general, the students admitted that the results obtained correspond to their perception of modern communication methods.

Question No. 1. Do you think social media influences the way we speak and write in our daily life? (yes - 176; no - 64).

It is obvious that the majority admit the fact that their online behavior affects everyday communication and that they are increasingly use abbreviations, shortenings and specific symbols. Perhaps this is the essence of the difference between generations before and after Facebook.

Question No. 2. Do you use smileys when writing e-mails, SMS, Twitter messages? (yes -201 ; no - 39).

The widespread affirmative answers illustrate writing practices of students. There is no doubt that the use of inserts and smileys presupposes some understanding by the communicator, i.e. literacy in social networks.

Question No. 3. When you text messages, do you think about grammar and punctuation rules? (yes - 199; no-41).

Such an asymmetry of answers with a predominant "yes" could demonstrate that students think about their form of expression, but we cannot be sure about the veracity of the answers, since quite often SMS contains only basic information. One of the possible reasons may be related to survey surrounding - in university setting. Although we cannot state this being completely certain in the fact.

Question No. 4. Do you post personal information in social networks? (yes -125; no 115).

As we can see here, the difference between positive and negative responses is almost the same. This may indicate that students are careless about sharing personal information. Although discussing this specific answer in seminars, students argued about the opportunity to keep the profile closed, i.e. personal. Perhaps the reason for such a division of answers could be the inaccurate question. It should be reformulated as follows: Do you publish personal information openly?

Question No. 5. Do you agree that social media minimizes or negates social distance? (yes - 161; no-79).

The answer is not surprising, since social media itself, especially the so-called new media, presupposes an egalitarian, horizontal structure of relationships. There is no hierarchy, no authority. At the same time, it also shows a tendency towards the loss of a more formal way of address.

Question No. 6. Does messaging (SMS, Twitter, Skype, WhatsApp, etc.) facilitate communication? Does it interfere communication? (yes - 157; no - 88).

It is obvious that students are optimistic about the future of social media communication. However, during the discussion at the seminar, some negative aspects also arose, namely, it 
was noted that the communication became more superficial, that a large number of "friends" or "followers" does not mean real friendships. Sometimes it can be confusing that there are people among your friends that you have never met and never interacted with in real life. You might be puzzled where and how you met these or that person whose life stories are now before your own eyes.

\section{Conclusion}

The topic of communication in philosophy acquires special significance in $20^{\text {th }}-21^{\text {st }}$ centuries because of new technologies development and the emergence of social networks. This changes the whole dynamics of the situation, since social media presupposes interactivity, reciprocity, and involvement. At the same time, negative factors appear - loss of privacy, excessive communication, social alienation, and addiction problems.

The author, who in the $19^{\text {th }}$ century predicted positive and negative sides of media dominance in culture and communication and in the history of philosophy, was the Danish philosopher and theologian Søren Kierkegaard. He pointed to such philosophical topics as individuality leveling and loss, the crowd as untruth, noise and the construction of a parallel social reality, anonymity. The press and public sphere encourage the ubiquitous commentators who are out of touch with real circumstamces. Especially the latter aspect is in parallel with today anonymous Internet commentators with their arrogance, envy and undisguised rudeness.

The concepts of a network society by Manuel Castell and Jan van Dyck characterize changes in the social structure and the formation of new mosaic clusters of communication.

New media paradigm has five special features (digitalization, convergence, hyperactivity, interactivity, virtuality), then the concept of social networks refers to social character, free media choice, authorship and free use.

The philosophy of Facebook (social networks) states the following: social media affects our using word "friend"; social media affects the way we think about autonomous social networks; social media affects our self-presentation; social media influences on our perception by others; social media affects our identity; social media influences relationshipkeeping behavior; social media affects our privacy.

A survey of 40 Russian students shows that although students are aware of the impact of social media on their daily communication patterns, they perceive them as a new natural environment for communication.

\section{References}

1. S. Kierkegaard, Conversations and Reflections (Ripol-Classic, Moscow, 2018).

2. M. Castells, Internet Galaxy: Reflections on the Internet, Business and Society (UFactoria, Ekaterinburg, 2004).

3. M. Castells, Information Age: Economy, Society and Culture (SU HSE, Moscow, 2000).

4. M. McLuhan, Media Understanding: External Extensions of a Person (Hyperborea; Kuchkovo field, Moscow, 2007).

5. D. Crystal, Language and the Internet. - 2nd ed. (Cambridge, MA, Cambridge University Press, 2006).

6. J. Dyk van, The Network Society. The Social Aspects of New Media (London, Thousand Oaks, New Delhiб SAGE Publications, 2006). 
7. S. Kierkegaard, Two Ages. - Princeton (Princeton University Press, New Jersey, 1978).

8. P. Levinson, New New Media (Allyn \& Bacon, Boston, 2009).

9. M. Lister, J. Dovey, S. Giddings, I. Grant, K. Kelly, New Media: A Critical Introduction (Routledge, London and New York, 2009).

10. R. Poole, Kierkegaard: the Indirect Communication (Charlottesville: the University Press of Virginia, 1993).

11. R. Shain, Philosophy Today 44 (4), 388-403 (2000).

12. M. Thust, S0ren Kierkegaard (Der Dichter des Religiosen, Munich, 1986).

13. D. E. Wittkower, Facebook and philosophy (Chicago and La Salle, Illinois: Open court, 2010).

14. F. Zimmerman, Das Wesen des GeistesimWerk Soren Kierkegaards (Diss. Munchen, 1969).

15. I.A. Zherebkina, Subjectivity and Gender. Gender Theory of the Subject in Modern Philosophical Anthropology (Moscow, 2007). 